\title{
Basta de indiferencia
}

\section{Enough of indifference}

María Dolores Martínez García ${ }^{a}$, Yovani Daniel Trejo Osorio ${ }^{b}$

\begin{abstract}
:
An overall vision of the current situation of our country and its big challenges that are needed for the transformation of society, which helps all Mexicans to enjoy a dignified life, is to raise awareness in each Mexican citizens around Mexican Republic and also who make decisions in the country, giving guidelines to hereditary responsibility in relation to the new generational gaps, where equality and new perspectives take part in a new Mexico, where the common good goes first rather than personal benefit.
\end{abstract}

Keywords:

Common benefit, society, economical model

\section{Resumen:}

La visión global de la situación en la actualidad de nuestro país y sus enormes desafíos que se necesitan para la transformación de la sociedad en general, que coadyuve para que todos los mexicanos gocen de una vida digna, es concientizar a cada uno de los ciudadanos en la República Mexicana y en especial a quienes toman decisiones del país, dando pauta a la responsabilidad hereditaria en relación a las nuevas brechas generacionales, donde se construya un México nuevo y justo para todos donde se anteponga el bien común antes del beneficio personal.

\section{Palabras Clave:}

Bien común, sociedad, modelo económico

\section{Introducción}

La publicación del libro Basta de indiferencia en el ejercicio 2016, contiene una segmentación de 10 capítulos, donde muestra el qué hacer para revertir los comportamientos y situaciones que destruyen el valor de la sociedad mexicana, pensando en una nueva construcción de México por encima de las diferencias existentes, fomentando el trabajo colaborativo con una ciudadanía participativa, comprometida y organizada que es permeada de solidaridad en un país que no puede esperar para la transformación deseada sanando las heridas y llagas que han lastimado y desfigurado el rostro de país en las últimas décadas.

\section{Desarrollo}

Capítulo uno. El hartazgo que la sociedad presenta, es mostrado por el autor, dando énfasis en las situaciones y comportamientos, que a través de los años, convierten a dicha sociedad en una cultura destructora y con falta de valor, situaciones que obstaculizan la transformación de México. El hartazgo mencionado es considerado como la punta de lanza para la construcción de las bases de un nuevo amanecer para México; impunidad, corrupción, pobreza, desigualdad social, inseguridad, desempleo, ilegalidad, injusticia, falta de respeto a derechos humanos y cinismo de los líderes son las situaciones y comportamientos destructivos que lastiman profundamente a los mexicanos.

\footnotetext{
a Autor de Correspondencia, Universidad Autónoma del Estado de Hidalgo, Instituto de Ciencias Económico Administrativas, Área Académica de Administración, ORCID:0000-0002-3606-8010,Email: maria_martinez1078@uaeh.edu.mx

b Universidad Autónoma del Estado de Hidalgo, Instituto de Ciencias Económico Administrativas, Alumno de la Maestría en Administración, ORCID: 0000-0001-8613-6053, Email: tr109730@uaeh.edu.mx
} 
De igual manera, el autor indica que, la sociedad ha comenzado a despertar de un letargo, asumiendo el rol correspondiente. La consciencia colectiva jamas antes habían llegado a elevado grado de fastidio y cansancio, lo cual orilla a la reconstrucción de la nación, liberandola del entorno mencionado, entorno que ha bloqueado la vida digna de los mexicanos.

En el capítulo dos se muestra los principales patrones de conducta que atan a México para su colocación dentro de las grandes naciones, siendo la indiferencia, el machismo, la pereza, la irresponsabilidad y el malinchismo los factores asociados a las conductas internas. De igual forma es importante mencionar que existen valores de la gente de nuestra nación que fortalecen a la misma; el emprendimiento y la creatividad, la solidaridad y la familia, los cuales unen al pueblo y se deben seguir promoviendo. En un mundo transformado con mayor complejidad, dinamismo e incertidumbre se debe aceptar el reto de llevar una revolución cultural nata en los mexicanos; comenzar a desarrollar un decálogo de competencias y patrones de conducta que se requieren en el siglo $\mathrm{XXI}$, para tener una vida y un trabajo digno, se incluyen las siguientes competencias:

- Liderazgo y tolerancia.

- Solución de problemas con enfoque colaborativo.

- Responsabilidad y orientación a resultados.

- Comunicación y dominio de lenguas extranjeras.

- Compromiso con el autoaprendizaje y profesionalismo.

- Integridad.

- Pensamiento crítico.

- Emprendimiento e innovación.

- Visión global.

- Responsabilidad social.

Existe una crisis de desconfianza y un debilitamiento dentro de los partidos políticos, donde el poder sufre transformaciones en todo el mundo, haciendo que sea fácil alcanzarlo, difícil administrarlo y sencillo perderlo. Se reflexiona sobre el comportamiento erróneo de algunos gobernantes y políticos que provocan una crisis de confianza; mientras que otros, originan nuevas fuerzas, ofreciendo una alternativa libre de compromisos, en búsqueda de recuperar la confianza. Retos no negociables que proclaman una democracia sólida, que consolida, el sentimiento de enfrentar el entorno que lastima.

Es frecuente que los gobiernos hagan mucho menos de lo que esperan los votantes, se necesita recuperar la confianza en el gobierno y en los dirigentes políticos, la clave para que se viva un renacimiento y mejoren su eficacia es que recuperen la capacidad de inspirar, estimular y movilizar a la gente, principalmente a los jóvenes, dando soluciones prácticas que México necesita, la situación anterior queda señalada en el capítulo tres.

En el capítulo cuatro el autor reflexiona sobre el modelo económico mexicano, el cual carece de capacidad para responder a demandas y retos que presenta la sociedad, ya que las instituciones y los protagonistas no aciertan en su implementación. Existen factores estructurales que son los que tienen que ver con el fortalecimiento de las instituciones y las modificaciones de las conductas equivocadas, dichos factores constituyen la esperanza para la reducción de la pobreza y la desigualdad social en el país, aunque sea en un tiempo a largo plazo; en el ámbito institucional, es necesario diseñar un marco adecuado, que contribuya a eliminar la corrupción en el actuar de los agentes económicos, tanto del sector público como del privado, así como también, conductas equivocadas, que a través del tiempo envenenan a la sociedad y como consecuencia, generan mayor pobreza y desigualdad social. Así mismo el eje de actuación de la educación, es considerada como herramienta para el desarrollo de competencias, habilidades y actitudes necesarias para que los mexicanos tengan la oportunidad de mejorar su situación actual y la de su familia.

Las reformas estructurales como detonador de un desarrollo sólido son descritas por el autor en el capítulo quinto, donde menciona a las mismas, las cuales han sido aprobadas siendo vitales para llevar a cabo una autentica y profunda transformación de México, donde el común denominador de ellas, tiene como objetivo, la transformación hacia un país moderno, acorde con el mundo competitivo al crear un ambiente de mayor justicia social y un progreso económico que beneficie a todos los mexicanos, con propósitos relevantes tales como, elevar la productividad del país, lo cual, detona el crecimiento y el desarrollo económico, fortalecer y ampliar los derechos que formen parte de la realidad cotidiana de los mexicanos, afianzar el régimen democrático y de libertades para transitar de una democracia electoral a una democracia que brinde resultados concretos, mediante diferentes tipos de reformas las cuales permitan alcanzarlos.

\section{En la productividad se encuentra:}

- Reforma energética

- Reforma en materia de telecomunicaciones y radiodifusión

- Reforma en materia de competencia económica

- Reforma financiera

- Reforma hacendaria

- Reforma laboral 
En derechos:

- Reforma educativa

- Código nacional de procedimientos penales

- Nueva ley de amparos

En democracia:

- Reforma política - electoral

- Reforma en materia de transparencia

- Sistema nacional anticorrupción

En el capítulo seis, el autor analiza la relevancia que tiene México y que sus líderes vivan un liderazgo autentico asumiendo el mismo por autoridad y no por poder. La falta o ausencia de liderazgo es uno de los principales retos que existen a nivel mundial, que deben ser afrontados si se desea un mundo más pleno para todos.

El arte del liderazgo requiere aprender 0 adquirir determinadas competencias o destrezas, pero que sobre todo demanda una coherencia profunda entre lo que se piensa y se dice, entre lo que se dice y se hace y cómo se piensa y cómo se actúa, es necesario influir y conseguir que la gente se comprometa en sus pensamientos, pasión y entrega para lograr los sueños del líder y en pro del bien común.

El líder por autoridad implica, conseguir que la gente se comprometa al logro de las metas que se tiene por medio del bien común debido a la influencia personal; así también, un líder por poder tiene la implicación de forzar u obligar a los demás a que logren dichas metas, aunque ellos no prefieran hacerlo, pero lo hacen debido al temor de las consecuencias que pueda traerles por parte del líder.

La esencia del modelo de liderazgo por autoridad, se considera como la construcción de un binomio aceptable entre servicio y sacrificio, donde el servicio conlleva a la creación de valor en los demás en cualquier momento que ellos lo requieran o lo pidan, que implica la identificación de forma oportuna de necesidades legitimas de los demás para finalmente satisfacerlas, por otra parte, el sacrificio consiste en anteponer el bien de los demás antes que el bienestar personal.

El autor refiere de forma detallada en el capítulo siete el triunfo del mérito y la derrota del privilegio siendo un reto no negociable, donde se hace hincapié en la urgencia de erradicar la cultura del privilegio y migrar a la cultura de la meritocracia en México. Se analiza el hartazgo que prevalece en la sociedad, frente al mediocre desempeño que tienen muchos funcionarios al servicio de la sociedad en puestos públicos, urge convencer a todos los protagonistas del país sobre la necesidad de vivir un liderazgo por autoridad y a la vez migrar de forma veloz de la cultura del privilegio a la cultura de la meritocracia.

La palabra mérito tiene un origen en la palabra latina meritum, que tiene como significado ganarse, merecer o hacerse digno de algo. Se tiene una gran cantidad de mexicanos talentosos y brillantes que provienen de la cultura del esfuerzo, pero que, ante una sociedad impregnada de la cultura del privilegio, se prescinden de ellos, error que estanca la construcción de una patria digna para todos; la contraparte a este hecho es que, el talento mexicano en la actualidad, es protagonista en el extranjero, al encontrar nulas oportunidades en la tierra que los vio nacer.

El qué hacer en la búsqueda de la reversión de los comportamientos y situaciones que destruyen el valor de la sociedad mexicana es explicado en el capítulo ocho; el autor muestra los comportamientos y situaciones destructoras de valor, de la misma forma propone acciones que deben llevarse a cabo para transformarlas en fortalezas, dando origen a una nueva época del país, cimentada en la justicia y en la dignidad de las personas.

Fortalecer el poder judicial, respetar el estado de derecho, incrementar la participación y presión ciudadana fortalecen el desarrollo social en México y propicias políticas públicas para la generación de empleos. La transformación deseada se logrará con un esfuerzo integral en el que todos los sectores de la sociedad se involucren y el Estado genere las políticas jurídicas necesarias que den certidumbre a la inversión nacional y extranjera en el marco de garantías para la generación de dichas fuentes de empleo.

El penúltimo capítulo, realiza hincapié en lo relevante para la construcción en un nuevo México, donde el pensamiento y el dialogo dan pauta para una nueva nación ante la complejidad y confusión que priva a nuestra nación. Es necesario trabajar de manera colaborativa, propositiva e innovadora, escuchando los diferentes puntos de vista para construir una sociedad más justa y digna para todos, este trabajo en equipo requiere de tres verbos que son: pensar, dialogar y actuar, permeando el modelo económico de solidaridad como alternativa para poder lograr el saneamiento de heridas del rostro sufriente de la nación.

México se caracteriza por ser un país con gran riqueza y diversidad social, étnica y cultural, donde coexisten las tradiciones indígenas con el legado colonial, los valores propios mestizos que por más de los siglos de independencia generan una cultura propia, enriquecida con las migraciones internacionales del siglo XIX propiciando una amplia gama de aportes religiosos $y$ 
culturales que conllevan a tradiciones que dan sentido al país de la actualidad.

Se requiere de un cambio cultural profundo que transforme las condiciones políticas y sociales en beneficio de la mayoría de los ciudadanos, de igual forma se necesita realizar cambios radicales en cada uno de los integrantes, viviendo los valores de la democracia y el actuar en pro del bien común y no solo en el beneficio de intereses propios, donde la decidida participación de todos es indispensable. Hacer juntos quiere decir construir el futuro del país, no a partir del genio solitario de un individuo, sino a partir de la colaboración de todos.

Se tiene que entender que es necesario demostrar frente al gobierno que no somos una masa de individuos aislados e incapaces de unirse para defender sus derechos y luchar por un mejor mañana para las nuevas generaciones, México se encuentra en el momento actual donde requiere una ciudadanía participativa, comprometida y organizada, qué exija a los gobernantes que cumplan con su misión que es servir y no servirse para su beneficio.

De forma detallada, en el último capítulo, el autor refiere que México no puede esperar, se tiene que actuar, no es un país fallido, pero exhorta la urgencia al fortalecimiento de lazos sociales; la nación, comenta el autor, es un guerrero indomable en circunstancias adversas a lo largo de la historia.

El escenario deseado que los mexicanos esperan conlleva ante todo a renunciar a la indiferencia y frivolidad de muchos integrantes y estar conscientes de que el gran reto es abatir los conflictos de manera oportuna, visualizando las áreas de oportunidad.

Los integrantes de la sociedad civil deben debatir de una manera profunda y seria la forma de generar el bien común permeando un modelo económico con enfoque solidario.

\section{Conclusiones}

Se analiza una visión de forma global de la situación nacional y los grandes desafíos que se presentan para la transformación de la sociedad, donde el fin último es buscar que los mexicanos cuenten con una vida digna.

Es necesario concientizar a ciudadanos y dirigentes sobre la responsabilidad que existe al momento de heredar a nuevas generaciones un mejor lugar.

Con la idea fija, que menciona, se es ciudadano para participar en la construcción del México nuevo, pero también, se requiere participar para ser ciudadano.
Es importante reconocer que no se debe olvidar permear el modelo económico de solidaridad ya que eso no garantiza que todo será fácil y que alcanzar la justicia social no se da de manera simple y sencilla. Cumplir el objetivo, se basa en la suma de esfuerzos y sacrificios de la sociedad, y con la profunda renuncia a la indiferencia y egoísmo social que prevalece en la comunidad mexicana.

Contar con hombres y mujeres apasionados por México, comprometidos y capaces de compartir talento y tiempo propio en beneficio de la comunidad, ciudad o estado, acarrea sin duda, una mejora en la transformación de la nación mexicana.

\section{Referencias}

[1]Ramírez, D.N. (2016). Basta de indiferencia. México: Mc Graw Hill. 